\title{
Ambulatory EMR Adoption in the USA: A Longitudinal Study
}

\author{
Jun Sun \\ U. of Texas Rio Grande Valley \\ jun.sun@utrgv.edu
}

\author{
Jorge A. Garcia \\ Johns Hopkins University \\ jgarci72@jhu.edu
}

\author{
Ying Wang \\ U. of Texas Rio Grande Valley \\ ying.wang01@utrgv.edu
}

\begin{abstract}
Based on a longitudinal national survey, this study examines the adoption of electronic medical records (EMR) by clinics in the USA between 2004 and 2014. A trend analysis suggests that government incentive, technological breakthrough and patient-centered care push the diffusion forward. The interaction among policy, technology and practice is likely to affect the decision-making of practitioners regarding EMR adoption. This study identifies clinic-, patient- and visit-related variables from the survey, and uses them to predict EMR adoption intention and usage in each year. The explanatory power of different variables changed over time in different ways, revealing how policy, technology, and practice influence EMR adoption together. The findings yield implications for the strategies and best practices of health IT diffusion.
\end{abstract}

\section{Introduction}

Electronic medical records (EMR) concern the continuous collection and utilization of digital health information of patients for better service outcomes [44]. Most of the EMR records were created, updated and maintained by healthcare providers for patient encounters in the ambulatory environment [24]. On one hand, more and more clinics have implemented EMR; on the other hand, there is still a big space for improvement such as sharing health information with other organizations and engaging patients in office settings [20]. Thus EMR adoption is not a simple decision that clinics can make based on their own needs. Rather they need to consider the requirements of other stakeholders.

Compared with paper-based approach, the EMR technology enhances healthcare services by reducing errors and improving quality [16, 11]. Yet the concerns of the cost, workload, and security associated with EMR lead to user resistance to the technology $[18,14$, 17]. Unless there is a clear incentive and/or it is absolutely necessary, healthcare providers are generally hesitant to adopt EMR. Compared with other health information technologies, therefore, the diffusion of EMR typically requires the support of national and even cross-nation strategies and architectures due to the requirements of data quality and interchangeability [23, 31].

Beginning in the new millennium, some developed countries such as the USA, UK, Canada and Switzerland started to implement EMR initiatives. Among them, the scale of EMR diffusion pushed by the USA government is most noticeable [7]. As part of the American Recovery and Reinvestment Act of 2009, the Health Information Technology for Economic and Clinical Health (HITECH) Act directs federal and state governments, health insurance companies and other big medical institutions to promote EMR adoption [5]. The legislature came up with both incentives $(\$ 44,000$ and $\$ 65,000$ for physicians under Medicare and Medicaid respectively) and penalties (reimbursement reduction) [6]. The goal is to achieve the "meaningful use" of EMR by healthcare providers [7]. At the end of 2010s, over 700,000 clinics and 5000 hospitals are expected to reach the goal through three stages in terms of medical data capturing, health information exchange, and clinical decision support [28].

Now that the "meaningful use" initiative is at its final stage in the USA, other countries all over the world may learn from its successes and lessons. This study examines how the interaction among government policy, technology advancement and healthcare practice affects EMR diffusion over time. Based on a systems perspective, it first develops a conceptual framework to identify the major factors that come into play when healthcare providers make decisions on EMR adoption. Then it identifies relevant variables form a national survey and conducts longitudinal analyses. The findings provide insights on the best practices to promote EMR adoption by healthcare providers. The experiences of USA are helpful for other countries at different stages of EMR diffusion. 


\section{A systems and contingency view}

From the ecological systems point of view, an organization adapts its operations to the changes in the environment, similar to the interaction between a living organism and the natural environment [8]. In addition, the contingency theory posits that the optimal course of actions for an organization to adapt to the changes depends upon both internal and external conditions or situations (i.e. contingencies) [41]. Based on such a perspective, the factors that influence providers' EMR adoption can be divided into two types: environmental factors (i.e. external contingencies) and organizational factors (i.e. internal contingencies) [30]. This study further classifies the organizational factors into clinic level and patient level, as shown in Figure 1.

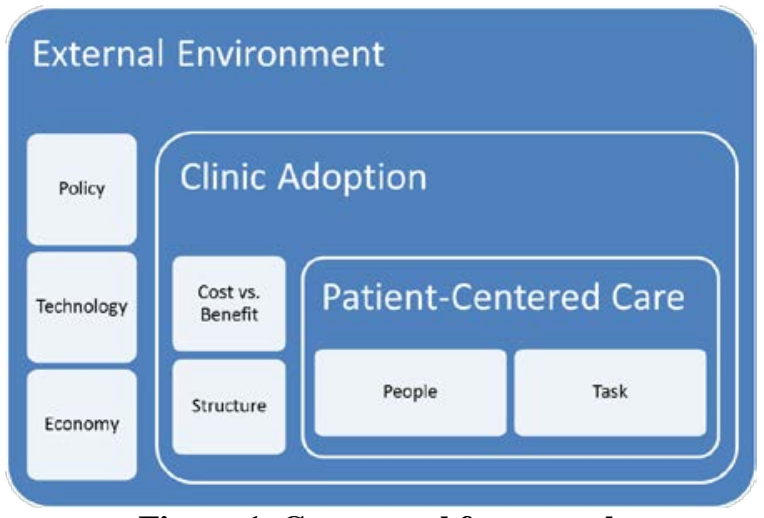

Figure 1. Conceptual framework

For a typical organization, external contingency factors include political/legal factors, technological factors, economic factors and social-cultural factors, and internal contingency factors include people, task, technology and structure [13]. In one country, socialcultural factors remain relatively stable for a long period of time. It is the changes in policy, technology and economy that make differences in EMR diffusion from external environment (economy not as directly under control as the others) [43]. At the patient level, people and task comprise the core of healthcare service. At the clinic level, providers mainly concern the cost and benefit associated with the technology and how compatible it is with the existing structure.

Separate studies have taken environmental influence and clinic characteristics into account but few have included the variables related to patient visits in the analyses of EMR adoption. Yet the most important aspect of healthcare operations is patient service encounter [25]. If a physician ignores a patent's needs in the meeting while using EMR, there are likely to be unintended consequences leading to poor service quality, trust compromise and even patient harm [37,
12]. The technology is supposed to increase patients' access to health information so that they can be more actively involved in their own care, leading to patientcentered care [4].

For patients, the benefits from EMR adoption have mainly two folds: improved healthcare quality from better services [11] and enhanced patient safety from reduced errors [16]. Patient-centered care based on the technologies like EMRs can actually reduce operating cost for physicians in the long run [39]. To promote the meaningful use of EMR, the US federal government encourages healthcare providers to adopt the technology [40]. On one hand, providers can get part of the implementation cost covered from Medicare and Medicaid; on the other, there is a monetary penalty for failing the meaningful use requirement (i.e. deduction from Medicaid and Medicare reimbursement). Whereas healthcare quality and patient safety can be viewed as indirect benefits to providers, the financial incentives from Medicare and Medicaid are direct benefits that drive them to adopt EMR [6].

Thus, the decision-making of providers on EMR adoption is primarily under the influence of government policy. Though customer-side considerations have indirect impacts on adoption decisions, patient involvement in healthcare operations (e.g. accessing appointment information, lab test results etc.) still contributes to the meaningful use of EMR. Most importantly, government policy intends to promote EMR diffusion for patient-center care [38, 45]. In this sense, the external policy environment and internal operation environment push the providers in the middle toward the same direction.

The advance in information and communication technology (ICT) is another important environmental element that facilitates EMR diffusion. In particular, the cloud computing technology emerged at about the same time when the USA government pushes the meaningful use of EMR [26]. It greatly enhances the interoperability of EMR for smooth health information exchange [3]. The service-oriented architecture releases application users of the responsibilities to maintain, upgrade and secure in-house systems [46].This is particularly important for relatively small clinics as they are limited in financial and technical resources in comparison with large organizations (e.g. hospitals) [42].

\section{Data and variables}

To evaluate the influences of environment-, clinicand patient-related factors on EMR adoption, this study compiled secondary data from the National Ambulatory Medical Care Survey (NAMCS) in the 
USA by the National Center for Health Statistics (NCHS). The latest data released to the public were collected in 2014. Starting in 2004, the annual survey included questions on EMR adoption. In later years, more questions were added but the basic one remained the same: Does the clinic use EMR in practice? Since 2006, another question on EMR adoption intention has been included: Does the clinic intend to install new EMR in the coming 18 months? These two questions are to be used as the outcome variables in this study. In addition, there are hundreds of other variables in the datasets (from less than 300 in 2004 to over 600 in 2014). Along the years, there have been some changes in these questions, but they are relatively stable compared with the EMR-related questions. All questions fall into two categories: clinic characteristics and patient visits, respectively. For each clinic, the values of the variables in the first category remain the same, but the values of those in the second vary from one patient to another.

Some researchers have utilized the NAMCS data to analyze EMR adoptions in an ambulatory healthcare setting. Most of the studies are descriptive in nature and does not identify adoption factors that may determine whether physicians are likely to adopt and use EMR. For instance, one study analyzed the most frequent EMR functionalities used by physicians [27]. This study conducts predictive analyses to find our relevant factors that make differences in EMR adoption. Furthermore, it keeps track of the changes in the variables and their relationships over 10 years. The longitudinal trends provide helpful insights on important factors at different stages of EMR diffusion.

To identify the relevant variables to EMR adoption and usage, this study consults the literature. Based on the existing studies, Figure 2 identifies the relevant variables in three categories: clinic, patient and visit. The unit of analysis of this study is clinic, but each record in the dataset is about a patient visit. Thus, each patient/visit variable needs to be aggregated by taking the average for each clinic. All the variables in the final compiled dataset are of either interval or binary natures so that they can be used in statistical analyses.

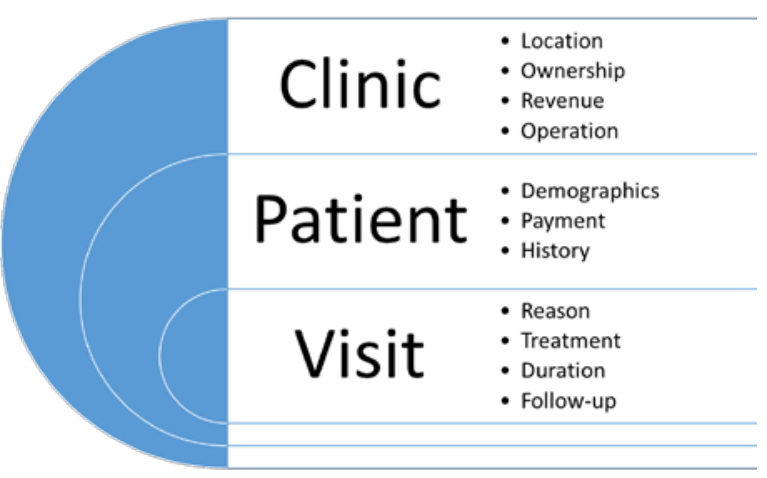

Figure 2. Variable categories

Table 1 summarizes the variables included in this study. Among the 26 variables, 2 are outcome variables, 11 are clinic variables, 9 are patient variables, and 4 are visit variables. Although the list does not include environment variables, the longitudinal analyses may reveal their influences in form of critical events that change the patterns or relationships dramatically.

Table 1. Variables selected for analyses

\begin{tabular}{|l|l|l|}
\hline Variable & Category & Description \\
\hline EMR & Outcome & Use EMR in practice? \\
\hline EMRINS & Outcome & Intend to install new EMR? \\
\hline Midwest & Clinic & Located in Midwest? \\
\hline South & Clinic & Located in South? \\
\hline West & Clinic & Located in West? \\
\hline MSA & Clinic & Metropolitan Area? \\
\hline Private & Clinic & Private Practice? \\
\hline Solo & Clinic & Solo practice? \\
\hline HomeVisit & Clinic & Home visits (last week)? \\
\hline HospitalVisit & Clinic & Hospital visits (last week)? \\
\hline AcceptNew & Clinic & Accepting new patients? \\
\hline RevMCAR & Clinic & \% Revenue from Medicare \\
\hline RevMAID & Clinic & \% Revenue from Medicaid \\
\hline Age & Patient & Age (in years) \\
\hline Male & Patient & Gender (Male?) \\
\hline Hispanic & Patient & Hispanic Ethnicity? \\
\hline White & Patient & White Race? \\
\hline Insured & Patient & Paid with insurance? \\
\hline PrimaryCare & Patient & Primary care physician? \\
\hline Referral & Patient & Patient referred? \\
\hline SeenBefore & Patient & Patient seen before? \\
\hline PastVisits & Patient & Past visits (12 months) \\
\hline Chronic & Visit & Chronic illness? \\
\hline NumMed & Visit & Number of medications \\
\hline TimeMD & Visit & Minutes with physician \\
\hline ReturnAppt & Visit & Return appointment made? \\
\hline
\end{tabular}

\subsection{Clinic variables}

First, researchers found that locations of healthcare providers in terms of urban classification (or 
metropolitan statistical area, MSA) and geographic region make a difference in EMR adoption [1, 15, 34]. Thus this study includes both types of location variables. Though clinics cannot change their locations, the results may help policy makers determine whether certain areas need special assistance to promote EMR diffusion. For instance, previous findings suggest practices in the western and Midwest regions of the United States were more likely to use EMRs [9, 15]. This study will find out whether such a pattern still persists along the years.

In terms of ownership structure (e.g. solo or nonsolo practices), researchers found that it plays some significant role in EMR adoption [19, 33]. To some extent, it determines the size of a clinic. A solo practice is usually small, and has constraints on the resources needed for EMR [10, 15, 22]. In addition to solo and non-solo ownership differentiations, this study establishes other physician characteristics, including: employment status (owner vs. employee or contractor) and physician type (physician group or other institution such as a hospital or an insurance company).

Researchers found the major sources of revenue also matter for EMR adoption by a clinic [9, 10]. As aforementioned, the HITECH Act imposes the requirement of EMR meaningful use with financial incentives and penalties on the clinics that get reimbursements from Medicaid/Medicare. This study will compare the results before and after the law's enactment in 2009. This policy event is expected to have an impact on the effects of revenue-related variables.

The nature of practice such as whether a clinic handles mainly inpatients or outpatients is found to have an impact on EMR adoption as well [2]. In this study, similar variables regarding whether a clinic conducts home visits and/or hospital visits are included. In addition, whether a clinic accepts new patients is used as a predictor related to practice.

\subsection{Patient variables}

Researchers usually include physicians' demographics like gender and age to predict their EMR adoption [35].Yet NAMCS data do not provide such information about individual physicians (as many clinics have multiple physicians). Rather there is demographic information about each patient. One study found that the race and ethnicity of patients have some influence on how their clinics use EMR [32]. In particular, Hispanic-serving physicians were found less likely to use EMR. With longitudinal observations, this study examines whether similar patterns hold. In addition, other demographic variables such as patient age and gender are also included.
How patients make payments (e.g. managed-care plans, Medicare, Medicaid, etc.) were found to make a difference on EMR adoption [21, 36]. To avoid the confusion with aforementioned revenue-related variables, this study rather focuses on whether patients are insured or not. With the enforcement of Obama care starting in 2010, more and more people get medical insurance. It is interesting to see whether such an environmental change has an impact on EHR adoption or not.

Few studies have taken patient history into account, but this study includes three history-related variables. The first question is: whether the patient was referred or not? It is expected that referred patients have the need to transfer medical records, and the use of EMR facilitates the process. The second question is: whether the patient was seen before? Compared with new patients, existing patients have accumulated medical records, and electronic records are easier to retrieve than paper records. The third question is: how many visits did the patient make during the past 12 months? This may be relevant to EMR adoption for the similar reason of record retrieval.

\subsection{Visit variables}

So far, few researchers have included variables related to patient visits into empirical studies on EMR adoption. However, physicians use EMR before, during and after each visit. The characteristics of patient service encounters should have some impacts on EMR adoption and use.

The reason of a visit concerns whether it is for a chronic illness or not. For other technologies like telemedicine, researchers found that their use may be helpful for chronically ill patients [29]. In this study, however, it is possible that patients with chronical diseases have historical paper records that take effort to be converted into electronic records. This might hinder the EMR adoption by a provider whose patients are mostly chronically ill. On the other hand, once the records of a patient are digitalized, it is easier for a physician to keep track of chronic disease progress. The results may reveal which force has the stronger effect on EMR adoption.

This study includes a treatment variable in terms of how many medications are prescribed for a visit. The rationale is that electronic prescription (eprescription) is a major component of EMR. If a physician needs to prescribe many medicines for his/her patients, EMR is helpful in this regard.

The duration variable captures the time that a patient spent with a physician in each visit. Rather than writing on paper, physicians enter medical notes into computers right away with EMR. On one hand, this 
may reduce the time with patients; on the other, physicians may spend time with patients explaining notes and results on computer screens. Thus, the results may be somewhat mixed.

Finally, the follow-up variable indicates whether a return appointment was made at the end of a visit. Like e-prescription, automatic reminders with emails or phone calls are made possible with EMR. If there is a high percentage of return appointments, providers may prefer EMR for a better handling of reminders.

\section{Descriptive analyses}

Spanning the years between 2004 and 2014, the compiled data set before aggregation consisted of 367,447 records and 16,153 clinics. The patient to clinic ratio shows the average number of patients elicited from each clinic in the sample. As depicted in Figure 3, there are on average 23 patient participants per clinic over the years. The number of clinics included in the survey jumped in 2012 from less than 1,500 to over 3,500 , and then declined (but still more than that in 2011 and before).

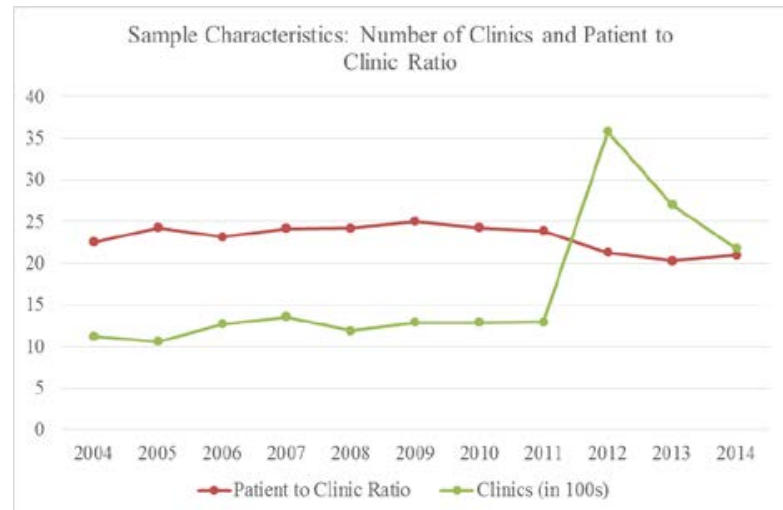

Figure 3. Number of clinics and patients per clinic

Then patient visit records were aggregated by taking the averages of patient and visit variables for each clinic. For instance, an interval variable like the age of each patient was converted to the average age of patients for each clinic. For another example, a binary variable like patient gender was converted to the proportion of male patients that visited each clinic. The aggregation changed the unit of analysis from visit to clinic, and the final dataset contains 16,153 records (the number of clinics).

Figure 4 illustrates the trend of EMR adoption. The two trend lines at the bottom shows the rate of EMR use, and the intention to install/upgrade new EMR systems, respectively. As indicated by the trend line at the top, the total of two exceeded $100 \%$ in the years of 2009 and 2014. This means that a noticeable proportion of the clinics are upgrading their EMR systems rather than installing new systems, otherwise the total should be at most $100 \%$ (i.e. existing systems + planned systems $=$ all systems existing or planned).

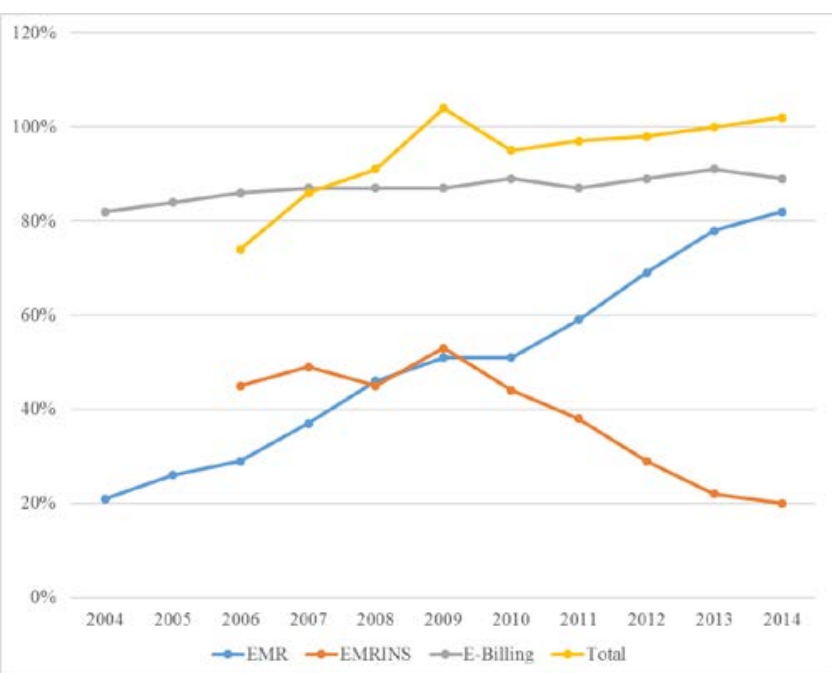

Figure 4. Trend of EMR adoption

The adoption rate of e-billing (which is not part of EMR) was included as the baseline as its rate was relatively stable over the years between $84 \%$ and $91 \%$. The clinics just need computers and Internet connections to log in the electronic claim portals of insurance companies. Thus e-billing adoption can be used as the ceiling of EMR adoption: if a clinic does not file electronic claims, it is not likely to use EMR either. Between 2008 and 2014, the total rate of EMR adoption and intention to install/upgrade new systems exceeded the adoption rate of e-billing by $10 \%$ on average, which was largely contributed by system upgrading. In particular, many clinics are switching to cloud-based EMR platforms from the original serverbased systems. This process is likely to last for a relatively long period of time.

Before 2008, both EMR existing use and adoption intention climbed up. The advance in technology was the main force behind. In 2008, the adoption intention declined probably due to the financial crisis. In 2009, there was a jump in overall EMR adoption (current use + adoption intention). This shows the effect of stimuli from HITECH incentives. In 2010, it regressed but then went steadily up. The year 2009 was also the last year that saw the rate of adoption intention exceeded that of current use. Then the gap between two became larger every year. Yet in 2014, there was a sign of flatout for both the upward trend of current use and the downward trend of adoption intention. On one hand, the EMR ambulatory market was approaching 
saturation; on the other hand, system upgrading was becoming dominant in adoption intention.

Figure 5 shows the rankings of EMR adoption by four regions. Before the end of 2011, the west region had been the top 2 but then its rank fell to the last in 2014. The south region saw the relatively steady climb from over the years. The mid-west and north east regions contrasted each other with $\cup$ and $\cap$ shapes respectively. The fluctuations suggest that government resources tend to be distributed to the places lagging behind so that they can catch up.

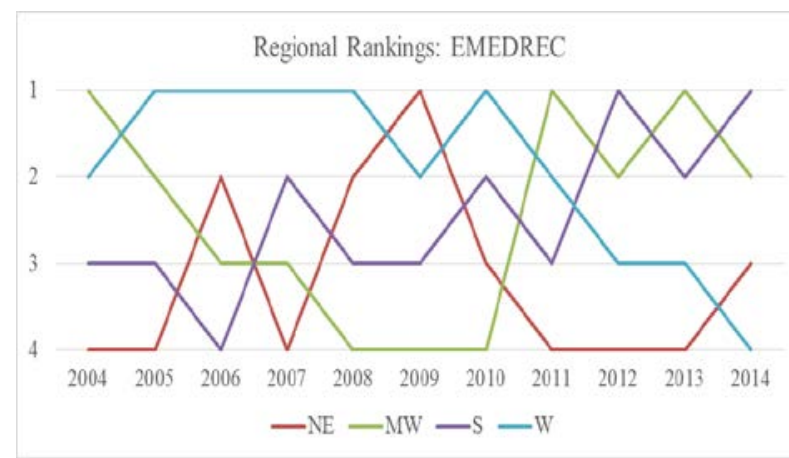

Figure 5. Ranking of EMR adoption by Regions

\section{Predictive Analysis}

In addition to the deceptive analyses, this study uses the explanatory variables related to clinic, patient and visit to predict each outcome variable in terms of current use or adoption intention in each year. As both outcome variables are binary in nature, logistic regression analyses were conducted. Tables 2 and 3 report the odds ratios with their observed significance levels for current use and adoption intention, respectively.

The most significant clinic variable was Solo. For current use, solo practices lagged behind in all the years. For adoption intention, the odds ratio for solo practices to plan EMR implementation or upgrading had been significantly lower until 2009. Similar pattern could be observed for the variable of Private. The HITECH incentives did help small private practices to catch up by providing necessary financial support. The emergence of cloud-based EMR platforms around 2010 also largely released them of technical burdens.

The next salient clinic variable was RevMAID (percentage of revenue from Medicaid). Its effect on adoption intention was mostly positive, especially in the years after 2009. However, its effect on current use was somewhat negative in general. Meanwhile, RevMCAR (percentage of revenue from Medicare) was not as significant. Medicaid has higher financial incentive and tougher monetary penalty than Medicare.
Also, Medicaid is income-based whereas Medicare is age-based. This suggests that the HITECH policy is very effective in helping the clinics that serve lower income population.

Consistent with the fluctuations of regional rankings, the significance levels of region variables changed across the years. Being in the metropolitan statistical areas (MSA) led to relatively high current use but low adoption intention (especially in 2013 and 2014). This suggests that the clinics in cities started earlier to adopt EMR than those in rural areas, and now the EMR market saturated in cities.

Compared with HomeVisit, HospitalVisit was more significant. This is explainable as there is a need to share medical records between hospitals and clinics if physician need to see their patients in different healthcare settings. Home visit, however, does not have such a requirement.

Among the patient variables, Insured was the most significant and it had positive effects on EMR adoption, especially toward the later years. This shows that Obama Care did promote EMR diffusion by increasing the insured population.

In the earlier years, the variable Hispanic had mostly negative effects on EMR adoption, but it had mostly positive effects in the later years. This may also be related to Obama Care, which significantly increased the proportion of insured people in the Hispanic population. Nevertheless, somewhat opposite trend can be observed for the variable White. Thus, the policy helps remove health disparities.

PrimaryCare, Referral and SeenBefore had relatively positive effects on adoption intention but negative effects on current use. The results somewhat confirms the conflict between the hard-to-discard paper records and easy-to-use electronic records.

The most salient visit variable was NumMed. The number of medication prescribed had a generally positive effect on EMR adoption. This is expected as eprescription is an important component of EMR.

The next salient variable was TimeMD. In this case, the time spent with the doctor had a somewhat negative correlation with EMR adoption. This seems to suggest that the use of EMR saves physicians time in general.

\section{Conclusion and implications}

The findings of this study provide some interesting insights on the interaction among policy, technology and practice. The most salient environmental factor is policy. The HITECH act and Obama Care are the major policy events that pushed EMR adoption forward. Meanwhile, technological advances have 
more gentle but long-lasting effects. The policy effects may soon wear out, but the conversion from serverbased systems to cloud-based platforms may sustain the EMR adoption for another decade after 2014, as it is expected that EMR will achieve a maximum market share for small practices in 2024 [15].

This study reveals the importance of patientcentered care in EMR adoption. For the first time, it includes patient visit variables in empirical analyses. The findings suggest that providers' decision-making regarding EMR adoption and use depends on the customers that they serve in addition to cost-benefit considerations. In this way, this study provides a comprehensive picture of EMR adoptions by taking both patient visits and clinic characteristics into account.

The findings provide other countries some helpful insights on how to promote their EMR diffusion based on the successes and lessons of USA. The government plays the major role in making policies to facilitate EMR adoption. EMR vendors must update their systems and services following the latest technological advances, especially cloud computing. Healthcare practitioners need to take the needs of their patients into consideration when they make adoption decisions.

For countries at different stages of EMR diffusion, there may be different strategies to promote it. At the beginning, a country may launch the EMR initiative by providing financial incentives to healthcare providers. Once the adoption rate is high enough to reach the critical mass, it is important that EMR vendors provide good system upgrading services. This will ensure that healthcare providers keep up with the technological trend and take advantage of the benefits it brings, such as cost, convenience (e.g. health information exchange), and security. The patient-centered care movement also makes the EMR diffusion sustainable. Patient engagement in healthcare is likely to push providers to adopt additional features of EMR systems. In this sense, patient education may be enhanced to help them participate in the shared use of EMR for better healthcare services.

\section{Table 2: Predicting Current Use of EMR}

\begin{tabular}{|c|c|c|c|c|c|c|c|c|c|c|c|}
\hline Variable & 2004 & 2005 & 2006 & 2007 & 2008 & 2009 & 2010 & 2011 & 2012 & 2013 & 2014 \\
\hline Midwest & $2.32^{* * * *}$ & $1.73^{*}$ & .88 & $1.67^{*}$ & $.64^{*}$ & .81 & .89 & $1.91^{* *}$ & $1.40^{* *}$ & $1.51^{*}$ & 1.04 \\
\hline South & 1.52 & 1.23 & .81 & $1.82^{* *}$ & .96 & .92 & 1.10 & 1.41 & $1.42^{* *}$ & 1.32 & 1.21 \\
\hline West & $1.86^{*}$ & $2.04^{* *}$ & 1.37 & $2.69^{* * * *}$ & 1.04 & .95 & 1.27 & $1.83^{* * * *}$ & $1.38^{* *}$ & 1.27 & .93 \\
\hline MSA & 1.76 & 1.36 & 1.35 & .89 & 1.09 & $1.76^{* *}$ & .84 & .87 & 1.15 & 1.39 & .97 \\
\hline Private & .87 & $.50^{* *}$ & .77 & $.40^{* * *}$ & $.59^{* *}$ & $.52^{* * *}$ & $.32^{* *}$ & $.42^{* *}$ & $.55^{* * *}$ & $.53^{* *}$ & $.44^{* *}$ \\
\hline Solo & $.43^{* *}$ & $.45^{* * * *}$ & $.52^{* *}$ & $.35^{* *}$ & $.59^{* * *}$ & $.39^{* * *}$ & $.47^{* *}$ & $.32^{* * *}$ & $.46^{* * *}$ & $.31^{* * *}$ & $.28^{* * *+}$ \\
\hline HomeVisit & 1.34 & .74 & 1.09 & .80 & 1.28 & 2.16 & .95 & .71 & 1.02 & $.53^{*}$ & 1.41 \\
\hline HospitalVisit & 1.23 & 1.07 & 1.21 & 1.24 & $1.62^{* * *}$ & 1.06 & 1.25 & 1.26 & $1.45^{* * * *}$ & 1.25 & $1.37^{*}$ \\
\hline AcceptNew & 2.54 & .74 & 2.26 & .61 & 1.22 & .99 & 1.54 & 1.43 & .97 & 1.32 & 1.39 \\
\hline RevMCAR & $1.31^{* *}$ & .97 & 1.15 & .99 & .82 & .89 & .95 & .92 & .95 & .85 & 1.16 \\
\hline RevMAID & .81 & .73 & .93 & $.80^{*}$ & 1.08 & 1.00 & $.69^{* * * *}$ & .99 & 1.04 & .91 & 1.07 \\
\hline Age & 1.00 & 1.00 & 1.00 & 1.00 & 1.01 & 1.00 & $.99^{* *}$ & $.99^{* *}$ & 1.00 & 1.01 & $.99^{* *}$ \\
\hline Male & 1.00 & 1.42 & $2.56^{* *}$ & $2.10^{*}$ & $2.02^{*}$ & 1.40 & 1.16 & 1.67 & 1.22 & .88 & .54 \\
\hline Hispanic & .73 & .38 & 1.03 & $.39^{* *}$ & 1.06 & .78 & 1.11 & 1.90 & $.44^{* *}$ & $2.89^{* *}$ & $.44^{*}$ \\
\hline White & 1.46 & .50 & 1.27 & 1.42 & $1.85^{*}$ & $2.10^{*}$ & 1.27 & .78 & .90 & 1.06 & 1.65 \\
\hline Insured & $3.28^{*}$ & .72 & 1.18 & 1.27 & .88 & 1.44 & $2.78^{* *}$ & $6.20^{* * *}$ & $2.17^{* * *}$ & $2.91^{* * *}$ & $2.14^{* *}$ \\
\hline PrimaryCare & 1.13 & .69 & 1.00 & $.65^{*}$ & 1.22 & .80 & $1.84^{* *}$ & .97 & 1.31 & $1.75^{* *}$ & $1.88^{* *}$ \\
\hline Referral & 1.06 & 1.40 & .90 & 1.29 & 1.04 & 1.38 & $1.44^{*}$ & $.68^{*}$ & 1.18 & 1.10 & $1.96^{* *}$ \\
\hline SeenBefore & $.28^{*}$ & .32 & .78 & .48 & .55 & $.40^{*}$ & .44 & $.16^{* * * *}$ & $.39^{* * * *}$ & $.24^{* * * *}$ & $.36^{*}$ \\
\hline PastVisits & $1.13^{* *}$ & 1.00 & 1.02 & 1.00 & 1.00 & 1.02 & .99 & 1.00 & .99 & 1.00 & .98 \\
\hline Chronic & .76 & .96 & $.49^{* * *}$ & .73 & $.60^{*}$ & $.48^{* *}$ & .83 & 1.07 & .91 & .98 & .95 \\
\hline NumMed & 1.00 & $1.24^{* * * *}$ & $1.19^{* * *}$ & $1.09^{*}$ & 1.08 & $1.16^{* * *}$ & $1.20^{* * * 4}$ & $1.20^{* * * *}$ & $1.08^{* * * *}$ & $1.19^{* * * *}$ & $1.18^{* * * *}$ \\
\hline TimeMD & 1.02 & .99 & 1.01 & 1.01 & 1.00 & 1.00 & 1.00 & 1.01 & 1.00 & $.99^{* *}$ & $.97^{* * *}$ \\
\hline ReturnAppt & .66 & .87 & .75 & 1.32 & .77 & .80 & 1.60 & 1.23 & .95 & 1.33 & 1.15 \\
\hline Constant & .01 & 4.93 & .11 & 1.00 & .73 & 1.25 & 1.85 & 1.89 & 2.95 & 2.91 & 16.16 \\
\hline
\end{tabular}

Note: * - Significant at 0.1 level; ** - Significant at 0.05 level; *** - Significant at 0.01 level. 
Table 3: Predicting Adoption Intention of EMR

\begin{tabular}{|c|c|c|c|c|c|c|c|c|c|}
\hline Variable & 2006 & 2007 & 2008 & 2009 & 2010 & 2011 & 2012 & 2013 & 2014 \\
\hline Midwest & $1.72^{* *}$ & .82 & 1.10 & $2.06^{* * *}$ & 1.23 & $.62^{*}$ & .82 & $.70^{*}$ & .72 \\
\hline South & 1.37 & 1.23 & 1.10 & $1.82^{* * *}$ & .78 & $.64^{* *}$ & $.77^{*}$ & .83 & .90 \\
\hline West & 1.07 & $.65^{*}$ & .96 & $1.96^{* * *}$ & .86 & $.65^{* *}$ & $.77^{*}$ & $.67^{*}$ & 1.00 \\
\hline MSA & .98 & 1.37 & 1.42 & .69 & .85 & 1.15 & 1.27 & $.60^{* *}$ & $.61^{*}$ \\
\hline Private & .68 & 1.02 & $.62^{*}$ & 1.36 & $1.46^{*}$ & 1.12 & .98 & .90 & 1.02 \\
\hline Solo & $.46^{* * *}$ & $.49^{* * *}$ & $.39^{* * *}$ & $.71^{* *}$ & .77 & 1.06 & .86 & .91 & 1.04 \\
\hline HomeVisit & 1.63 & .93 & 1.55 & 1.22 & .84 & 1.48 & 1.24 & 1.42 & $.26^{*}$ \\
\hline HospitalVisit & .99 & $1.50^{* *}$ & 1.12 & .95 & .98 & 1.11 & 1.03 & 1.11 & 1.22 \\
\hline AcceptNew & 2.32 & 2.09 & 1.78 & 1.99 & 1.46 & 2.58 & $1.70^{*}$ & 1.70 & .84 \\
\hline RevMCAR & .97 & 1.11 & 1.15 & .95 & 1.10 & 1.10 & 1.12 & 1.17 & .96 \\
\hline RevMAID & 1.19 & $1.60^{* * *}$ & $1.36^{*}$ & .96 & 1.13 & .83 & $1.20^{*}$ & $1.38^{* *}$ & $1.32^{*}$ \\
\hline Age & 1.01 & .99 & 1.00 & 1.01 & 1.00 & $1.01^{* *}$ & 1.01 & 1.00 & 1.01 \\
\hline Male & .86 & .66 & .76 & 1.27 & .90 & $.49^{*}$ & .91 & .84 & .79 \\
\hline Hispanic & 1.19 & 1.12 & .46 & $2.25^{*}$ & $2.16^{*}$ & $2.01^{*}$ & $1.94^{* *}$ & 1.09 & 1.57 \\
\hline White & 1.19 & .59 & 1.37 & $.49^{*}$ & .90 & .84 & $.59^{* *}$ & .87 & .94 \\
\hline Insured & $2.27^{*}$ & .91 & .80 & 1.01 & $2.11^{*}$ & 1.27 & .87 & .82 & 1.17 \\
\hline PrimaryCare & 1.20 & 1.46 & $.55^{* *}$ & 1.00 & .89 & $1.68^{*}$ & .89 & .76 & .79 \\
\hline Referral & .82 & .79 & 1.26 & 1.05 & 1.16 & .92 & 1.00 & $1.40^{*}$ & $.68^{*}$ \\
\hline SeenBefore & 1.28 & .47 & 2.61 & 1.38 & 2.30 & $2.89^{*}$ & $1.85^{*}$ & 1.60 & .71 \\
\hline PastVisits & .97 & $.96^{*}$ & $.94^{* *}$ & .98 & $.95^{* *}$ & .98 & .99 & .99 & 1.00 \\
\hline Chronic & .84 & 1.29 & 1.26 & 1.20 & 1.08 & 1.07 & .95 & .75 & .93 \\
\hline NumMed & .99 & 1.07 & 1.05 & .99 & .97 & $.92^{*}$ & .97 & .99 & $.92^{* * *}$ \\
\hline TimeMD & 1.00 & .99 & .99 & $.98^{* *}$ & 1.01 & $.98^{* *}$ & $.99^{* * *}$ & $1.02^{* * *}$ & 1.01 \\
\hline ReturnAppt & .80 & $.49^{* *}$ & .78 & 1.52 & .73 & .59 & 1.15 & .97 & .79 \\
\hline Constant & .15 & 1.65 & .36 & .40 & .12 & .18 & .21 & .70 & .45 \\
\hline
\end{tabular}

Note: * - Significant at 0.1 level; ** - Significant at 0.05 level; *** - Significant at 0.01 level. 


\section{References}

[1] J. Adler-Milstein, J. Everson and S.-Y. D. Lee, "Sequencing of EHR adoption among US hospitals and the impact of meaningful use", Journal of the American Medical Informatics Association, 21 (2014), pp. 984-991.

[2] J. S. Ash and D. W. Bates, "Factors and forces affecting EHR system adoption: report of a 2004 ACMI discussion", Journal of the American Medical Informatics Association, 12 (2005), pp. 8-12.

[3] A. Bahga and V. K. Madisetti, "A cloud-based approach for interoperable electronic health records (EHRs)", IEEE Journal of Biomedical and Health Informatics, 17 (2013), pp. 894-906.

[4] S. C. Bergeson and J. D. Dean, "A systems approach to patient-centered care", Journal of the American Medical Association, 296 (2006), pp. 2848-2851.

[5] D. Blumenthal, "Launching hitech", New England Journal of Medicine, 362 (2010), pp. 382-385

[6] D. Blumenthal, "Stimulating the adoption of health information technology", New England journal of medicine, 360 (2009), pp. 1477-1479.

[7] D. Blumenthal and M. Tavenner, "The "meaningful use” regulation for electronic health records", New England Journal of Medicine, 2010 (2010), pp. 501-504.

[8] U. Bronfenbrenner, Ecological systems theory, Jessica Kingsley Publishers, 1992.

[9] C. W. Burt, E. Hing and D. Woodwell, "Electronic medical record use by office-based physicians: United States, 2005", Health E-Stats (2006).

[10] C. W. Burt and J. E. Sisk, "Which physicians and practices are using electronic medical records?", Health Affairs, 24 (2005), pp. 1334-1343.

[11] R. D. Cebul, T. E. Love, A. K. Jain and C. J. Hebert, "Electronic health records and quality of diabetes care", New England Journal of Medicine, 365 (2011), pp. 825833.

[12] C.-S. Chang, S.-Y. Chen and Y.-T. Lan, "Service quality, trust, and patient satisfaction in interpersonal-based medical service encounters", BMC health services research, 13 (2013), pp. 22.

[13] J. Child, Organization: contemporary principles and practice, John Wiley \& Sons, 2015.

[14] L. Colligan, H. W. Potts, C. T. Finn and R. A. Sinkin, "Cognitive workload changes for nurses transitioning from a legacy system with paper documentation to a commercial electronic health record", International journal of medical informatics, 84 (2015), pp. 469-476.
[15] C. M. DesRoches, E. G. Campbell, S. R. Rao, K. Donelan, T. G. Ferris, A. Jha, R. Kaushal, D. E. Levy, S. Rosenbaum and A. E. Shields, "Electronic health records in ambulatory care-a national survey of physicians", New England Journal of Medicine, 359 (2008), pp. 50-60.

[16] M. S. Donaldson, J. M. Corrigan and L. T. Kohn, To err is human: building a safer health system, National Academies Press, Washington, DC, 2000.

[17] J. L. Fernández-Alemán, A. Sánchez-Henarejos, A. Toval, A. B. Sánchez-García, I. Hernández-Hernández and L. Fernandez-Luque, "Analysis of health professional security behaviors in a real clinical setting: An empirical study", International journal of medical informatics, 84 (2015), pp. 454-467.

[18] N. S. Fleming, S. D. Culler, R. McCorkle, E. R. Becker and D. J. Ballard, "The financial and nonfinancial costs of implementing electronic health records in primary care practices", Health Affairs, 30 (2011), pp. 481-489.

[19] E. W. Ford, N. Menachemi and M. T. Phillips, "Predicting the adoption of electronic health records by physicians: when will health care be paperless?", Journal of the American Medical Informatics Association, 13 (2006), pp. 106-112.

[20] M. F. Furukawa, J. King, V. Patel, C.-J. Hsiao, J. Adler-Milstein and A. K. Jha, "Despite substantial progress in EHR adoption, health information exchange and patient engagement remain low in office settings", Health Affairs (2014), pp. 10.1377/hlthaff. 2014.0445.

[21] M. F. Furukawa, T. Raghu, T. J. Spaulding and A. Vinze, "Adoption of health information technology for medication safety in US hospitals, 2006", Health Affairs, 27 (2008), pp. 865-875.

[22] D. Gans, J. Kralewski, T. Hammons and B. Dowd, "Medical groups' adoption of electronic health records and information systems", Health affairs, 24 (2005), pp. 13231333.

[23] T. D. Gunter and N. P. Terry, "The emergence of national electronic health record architectures in the United States and Australia: models, costs, and questions", Journal of medical Internet research, 7 (2005), pp. e3.

[24] J. L. Habib, "EHRs, meaningful use, and a model EMR", Drug Benefit Trends, 22 (2010), pp. 99-101.

[25] A. Hausman, "Modeling the patient-physician service encounter: improving patient outcomes", Journal of the Academy of Marketing Science, 32 (2004), pp. 403-417.

[26] B. Hayes, "Cloud computing", Communications of the ACM, 51 (2008), pp. 9-11.

[27] C.-J. Hsiao, E. Hing, T. C. Socey and B. Cai, "Electronic medical record/electronic health record systems 
of office-based physicians: United States, 2009 and preliminary 2010 state estimates", National Center for Health Statistics (2010).

[28] A. K. Jha, "Meaningful use of electronic health records: the road ahead", Journal of the American Medical Association, 304 (2010), pp. 1709-1710.

[29] D. P. John, O. M.-A. Milton, C. M. Evan, L. Ilta and F. Roosevelt, "Access to Mobile Communication Technology and Willingness to Participate in Automated Telemedicine Calls Among Chronically Ill Patients in Honduras", Telemedicine \& e-Health, 16 (2010), pp. 10301041.

[30] A. S. Kazley and Y. A. Ozcan, "Organizational and environmental determinants of hospital EMR adoption: a national study", Journal of medical systems, 31 (2007), pp. 375-384.

[31] P. Kierkegaard, "Electronic health record: Wiring Europe's healthcare", Computer law \& security review, 27 (2011), pp. 503-515.

[32] C. Li and D. West - Strum, "Patient Panel of Underserved Populations and Adoption of Electronic Medical Record Systems by Office - Based Physicians", Health services research, 45 (2010), pp. 963-984.

[33] N. Menachemi, "Barriers to ambulatory EHR: who are'imminent adopters' and how do they differ from other physicians?", Journal of Innovation in Health Informatics, 14 (2006), pp. 101-108.

[34] N. Menachemi and R. G. Brooks, "EHR and other IT adoption among physicians: results of a large-scale statewide analysis", Journal of Healthcare Information Management, 20 (2006), pp. 79.

[35] N. Menachemi, D. Burke and R. G. Brooks, "Adoption Factors Associated with Patient Safety - Related Information Technology", Journal for healthcare quality, 26 (2004), pp. 39-44.

[36] N. Menachemi, N. Hikmet, A. Bhattacherjee, A. Chukmaitov and R. G. Brooks, "The effect of payer mix on the adoption of information technologies by hospitals", Health Care Management Review, 32 (2007), pp. 102-110.

[37] B. Middleton, M. Bloomrosen, M. A. Dente, B. Hashmat, R. Koppel, J. M. Overhage, T. H. Payne, S. T. Rosenbloom, C. Weaver and J. Zhang, "Enhancing patient safety and quality of care by improving the usability of electronic health record systems: recommendations from AMIA", Journal of the American Medical Informatics Association, 20 (2013), pp. e2-e8.

[38] R. H. Miller, C. West, T. M. Brown, I. Sim and C. Ganchoff, "The value of electronic health records in solo or small group practices", Health Affairs, 24 (2005), pp. 11271137.
[39] C. B. Noteboom, S. P. Motorny, S. Qureshi and S. Sarnikar, Meaningful Use of Electronic Health Records for Physician Collaboration: A Patient Centered Health Care Perspective, System Sciences (HICSS), 2014 47th Hawaii International Conference on, IEEE, Hawaii, 2014, pp. 656666.

[40] S. Qureshi, C. Noteboom and A. M. Schumaker, Mobile Access for Patient Centered Care: The Challenges of Activating Knowledge through Health Information Technology, System Sciences (HICSS), 2015 48th Hawaii International Conference on, IEEE, Hawaii, 2015, pp. 3227-3236.

[41] S. W. Richard, "Organizations: Rational, natural, and open systems", Aufl., Englewood Cliffs (NJ) (1992).

[42] J. J. Rodrigues, I. de la Torre, G. Fernández and M. López-Coronado, "Analysis of the security and privacy requirements of cloud-based electronic health records systems", Journal of medical Internet research, 15 (2013), pp. e186.

[43] S. R. Simon, R. Kaushal, P. D. Cleary, C. A. Jenter, L. A. Volk, E. G. Poon, E. J. Orav, H. G. Lo, D. H. Williams and D. W. Bates, "Correlates of electronic health record adoption in office practices: a statewide survey", Journal of the American Medical Informatics Association, 14 (2007), pp. 110-117.

[44] N. S. Skolnik, Electronic medical records, Springer, New York, NY, 2011.

[45] T. G. Thompson and D. J. Brailer, "The decade of health information technology: delivering consumer-centric and information-rich health care", Washington, DC: US Department of Health and Human Services (2004).

[46] W.-T. Tsai, X. Sun and J. Balasooriya, Serviceoriented cloud computing architecture, Information Technology: New Generations (ITNG), 2010 Seventh International Conference on, IEEE, 2010, pp. 684-689. 